\title{
Application of Least Squares Estimation Techniques in 2D Conformal Coordinates Transformation from Local to National
}

\author{
Ehigiator M. O. ${ }^{1}$, Oladosu S. O. ${ }^{2}$ \& Ehigiator-Irughe, R. ${ }^{2, *}$ \\ ${ }^{1}$ Department of Physics, Benson Idahosa University, Benin City, Nigeria \\ ${ }^{2}$ Department of Geomatics, University of Benin, Benin City, Nigeria \\ Corresponding Author: *raphael.ehigiator@uniben.edu
}

\begin{abstract}
A two-dimensional conformal coordinate transformation is a similarity transformation which is also known as the four parameter transformation since it maintains scale relationships between the two coordinates system. This transformation type uses a mathematical model that establish a geometrical relationship between coordinates of points in different reference frames. It gained wider acceptance because of its capability to retain the shape of an area represented. This paper utilizes three control points; PT02, PT03 and PT04 to compute the transformation parameters and later all validated the derived coordinates of point PT04 known in the local system to national system using manual computation check. The second approach was to derive the transformation parameters using four control points. The result obtained was validated and found to agree with the derived national coordinates system for point PT07. Subsequently, all other points within the areas covered in the scope of work were transformed by writing script and running it in MATLAB software environment. The total area covered was 457.457hectares.
\end{abstract}

Keywords: Kainji Dam, Conformal, Coordinate Transformation, DGPS

\subsection{Introduction}

This project was carried out around Kainji dam area of Nigeria aimed at transforming coordinates in the local coordinates system to national coordinates system. The survey of area covering about 457.457hectares was undertaken for deformation monitoring purpose. Trimble DGPS R8 was deployed to acquire spatial data by taken measurements on control points PT02, PT03, PT04 and other points within the study area. The coordinates of these three control points were first defined in a local reference frame. The transformation process followed in this paper enables us to transform these local control points to Minna reference datum which is the Nigeria national reference frame system used for her mapping purposes.

Nigeria as a country is covered with first-order triangulation chains and traverse control networks. These networks were computed on the Nigerian geodetic datum which was established by astrogeodetic method with its origin located at station L40 opposite police secondary school. (It is a local geodetic datum termed "Minna B" datum because that which is applied in the west of the Republic of Cameroun is called "Minna A"). The Minna B datum is based on the Clarke 1880 ellipsoid with the following parameters; Semi-major axis, a $=6378249.145 \mathrm{~m}$; Flattening, $\mathrm{f}=1 / 293.465$. (Uzodinma and EhigiatorIrughe, 2013). The L40 origin has the following adopted geodetic co-ordinates (Uzodinma and Ezenwere, 1993): Latitude $\varphi=09^{\circ} 38^{\prime} 09^{\prime \prime} \mathrm{N}$, Longitude $\lambda=06^{\circ} 30^{\prime} 59^{\prime \prime} \mathrm{E}$, and Height $=279.6 \mathrm{~m}$ above the geoid.

Coordinate transformation from a local system is often encountered in Geomatics operations. There are cities and towns whose coordinate system are in local. There is need to transform the local coordinates system to the National. This can only be achieved if the minimum of two controls in the local system also has coordinates in the national system. Control points PT02, PT03 and PT04 are stations with both local coordinates system and national coordinates system, this enabled us to develop the mathematical 
model for transforming other points whose coordinates are still in the local coordinate system. Trimble GNSS R8 receiver was used to define the coordinates of these three control stations in national coordinates system. Once these relationships is established, it is then possible to determine the transformation parameters needed for all other points to be transformed.

\subsection{Study Area}

The study area is as shown in figure 1; that is, the google earth satellite imagery for clearer view. The coordinates of Kainji dam is given as; $09^{\circ} 51^{\prime} 45^{\prime \prime} \mathrm{N}$ and $04^{\circ} 36^{\prime} 48^{\prime \prime} \mathrm{E}$.

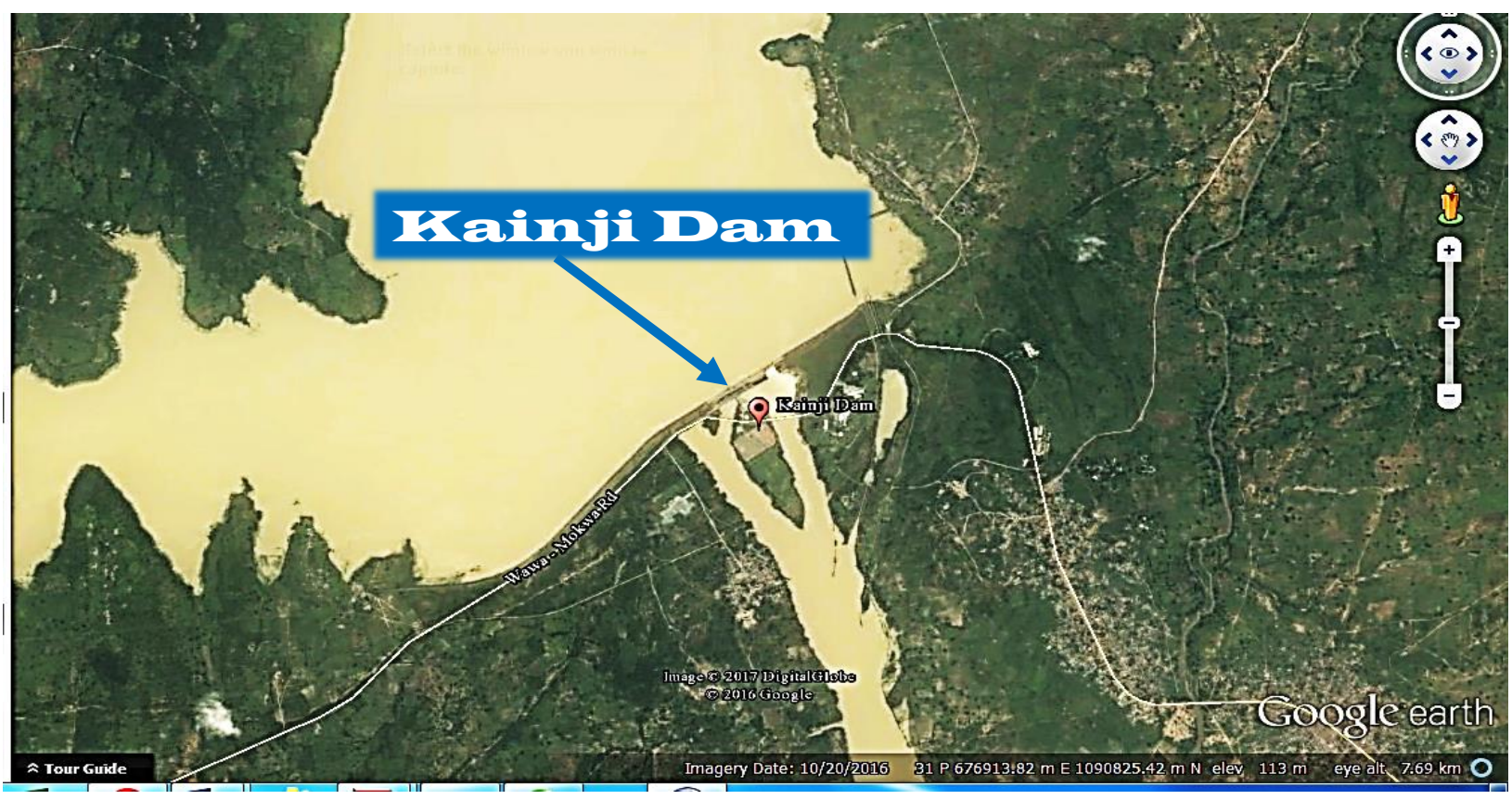

Figure 1: Google map imagery of the study area. Source (Google Earth)

\subsection{Coordinates System}

Coordinates systems may be in Local (assumed), National (NTM) and Universal (UTM). Whatever coordinates systems adopted, it is possible to transform between one system and another provided some points are known which are common to both systems. One of the methods of coordinates transformation is the conformal transformation treated in this paper.

\subsection{Types of Transformation}

Different types of transformation exist which are use based on the user's choice and what they tend to achieve. Some of them are; affine, polynomial, projective, etc. Mikhail (1976), observed that the effect of a transformation on a $2 \mathrm{D}$ or 3D object will vary from a simple change of location and orientation (with no change in shape or size) to a uniform change in scale (no change in shape) and finally to changes of shape and size of different degrees of nonlinearity. One of the most common transformations in Geomatics applications, which shall be discussed in this paper, is the 2D conformal, its achievement procedures and due to its ability to preserve angles and shape of objects.

\subsection{Materials/Method}

\subsection{Instrumentation}

i. 1x Trimble Dual frequency GPS R8 'Base Station' receiver.

ii. $2 \mathrm{x}$ Trimble Dual Frequency GPS R8 'Rover' receiver.

iii. Data Processing Computer. 


\subsection{Determination of Conformal Coordinate Transformation Parameters}

\subsubsection{Scaling}

Scaling is one of the most important parameter to be considered in two-dimensional conformal coordinate transformation. It is usually determined by the application of the following mathematical model.

$$
S=\frac{\sqrt{(\Delta N)^{2}+(\Delta E)^{2}}}{\sqrt{(\Delta x)^{2}+(\Delta y)^{2}}}
$$

Where; $\Delta \mathrm{N}, \Delta \mathrm{E}, \Delta \mathrm{x}$ and $\Delta \mathrm{Y}$ are the changes in the nothing and easting coordinates of the control points in the national and local systems respectively.

\subsubsection{Rotation}

In order to make points $\left(\mathrm{x}_{\mathrm{A}}, \mathrm{Y}_{\mathrm{A}}\right)$ in a local system coincide or correspond with points $\left(\mathrm{E}_{\mathrm{A}}, \mathrm{N}_{\mathrm{A}}\right)$ in a standard system rotation is required. This can be achieved by using the relation.

Rotation, $\theta=\alpha+\beta$ where;

$$
\begin{aligned}
& \alpha=\tan ^{-1}\left(\frac{x_{B}-x_{A}}{y_{B}-y_{A}}\right) \\
& \beta=\tan ^{-1}\left(\frac{E_{B}-E_{A}}{N_{B}-N_{A}}\right)
\end{aligned}
$$

\subsection{Translations in $E$ and $N$}

The third step for a successful transformation is to compute $\mathrm{T}_{E}$ and $\mathrm{T}_{N}$ of coordinates using equations (4a) to (4d);

$T_{E}=E_{A}-E_{A}^{\prime}$

$T_{N}=N_{A}-N_{A}^{\prime}$

Similarly,

$T_{E}=E_{B}-E^{\prime}{ }_{B}$

$T_{N}=N_{B}-N^{\prime}{ }_{B}$

\subsection{Formulation of the mathematical model}

In order to develop the mathematical model needed for transformation, consider Figure 2.

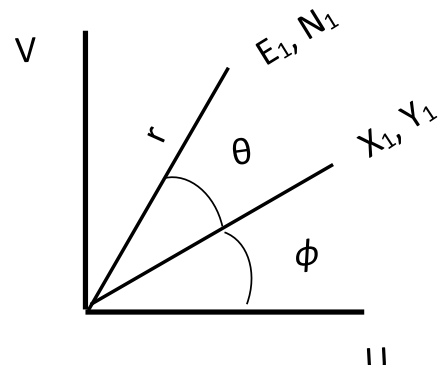

Figure 2: Sketch of the relationship

From the sketch shown in Figure 2, the following equations can be formulated. 


$$
\left.\begin{array}{l}
E_{1}=r \operatorname{Cos} \phi \operatorname{Cos} \theta-r \operatorname{Sin} \phi \operatorname{Sin} \theta \\
N_{1}=r \operatorname{Cos} \phi \operatorname{Cos} \theta-r \operatorname{Sin} \phi \operatorname{Sin} \theta
\end{array}\right\}
$$

Substitute equation (5) into equations (6) we have;

$$
\left.\begin{array}{l}
E_{1}=X_{1} \operatorname{Cos} \theta-Y_{1} \operatorname{Sin} \theta \\
N_{1}=Y_{1} \operatorname{Sin} \theta+X_{1} \operatorname{Cos} \theta
\end{array}\right\}
$$

By applying scale factor to equation (6) we have;

$$
\left.\begin{array}{l}
E_{a}=S X_{a} \operatorname{Cos} \theta-S Y_{a} \operatorname{Sin} \theta \\
N_{a}=S Y_{a} \operatorname{Sin} \theta+S X_{a} \operatorname{Cos} \theta
\end{array}\right\}
$$

Where;

$\mathrm{E}_{a}$; is the easting coordinate in the national system at point ' $\mathrm{a}$ ' $\mathrm{N}_{a}$; is the northing coordinate in the national system at point ' $\mathrm{a}$ ' $\mathrm{X}_{a}$; is the easting coordinate in the local system at point ' $\mathrm{a}$ ' $\mathrm{Y}_{a}$; is the easting coordinate in the local system at point ' $\mathrm{a}$ ' $\theta$; rotational angle

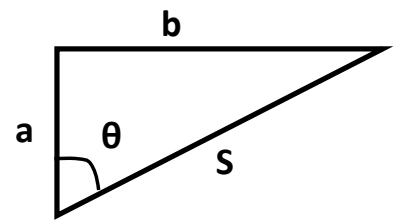

Figure 3: Representing the relationship

$$
\begin{aligned}
& \operatorname{Sin} \theta=\frac{b}{a}, a=S * \operatorname{Sin} \theta, b=S * \operatorname{Cos} \theta \\
& E_{A}=X_{A} \operatorname{Cos} \theta-Y_{A} \operatorname{Sin} \theta+T_{E} \\
& N_{A}=Y_{A} \operatorname{Sin} \theta+X_{A} \operatorname{Cos} \theta+T_{N} \\
& E_{A}=a X_{A}-b Y_{A}+T_{E} \\
& N_{A}=a Y_{A}+b X_{A}+T_{N}
\end{aligned}
$$

Adding residuals to equations (9a) and (9b) the observation equation can be written as shown in equations (10a) and (10b);

$$
\begin{aligned}
& E_{A}+V_{E}=a X_{A}-b Y_{A}+T_{E} \\
& N_{A}+V_{N}=a Y_{A}+b X_{A}+T_{N}
\end{aligned}
$$

Three control points are sufficient to successfully carry out the transformation. The solution to determine the transformation parameters can be formulated into a matrix algebra.

\subsubsection{Developing the designed matrix for observation equation model using three control points}

The designed matrices will be in the form;

$A X=L+V$ 
$A=\left[\begin{array}{cccc}X_{a} & -Y_{a} & 1 & 0 \\ Y_{a} & X_{a} & 0 & 1 \\ X_{b} & -Y_{b} & 1 & 0 \\ Y_{b} & X_{b} & 0 & 1 \\ X_{c} & -Y_{c} & 1 & 0 \\ Y_{c} & X_{c} & 0 & 1\end{array}\right], X=\left[\begin{array}{c}a \\ b \\ T_{E} \\ T_{N}\end{array}\right], L=\left[\begin{array}{c}X_{a} \\ Y_{a} \\ X_{b} \\ Y_{b} \\ X_{c} \\ Y_{c}\end{array}\right]$, and $\mathrm{V}=\left[\begin{array}{c}V_{E_{A}} \\ V_{N_{A}} \\ V_{E_{B}} \\ V_{N_{B}} \\ V_{E_{c}} \\ V_{N_{c}}\end{array}\right]$

Where;

$\mathrm{A}=$ Vector of adjusted parameters, $\mathrm{X}=$ vector of unknown parameters, $\mathrm{L}=$ vector of observed parameters and $\mathrm{V}=$ residual error.

This system can be solved using un-weighted least squares method in matrix form as in equation (12). Least squares emphasized that the sum of squares of the residual errors must be minimum.

$$
X=\left(A^{T} A\right)^{-1} A^{T} L
$$

\subsection{Results and Discussion}

Table 1, shows the coordinate data whose values are known in both local and national system used in the transformation process. Thus, in the local system, coordinates of three points were known but in national system only two points were known whilst the third point to be determine by transformation. But the minimum requirement is at least two points in the local system. The solution from equation (12) can be manipulated using MATLAB. The data from the two control stations are formulated as follows.

Table 1: Input data

\begin{tabular}{ccccc}
\hline Point & \multicolumn{2}{c}{ Local Coordinates } & \multicolumn{2}{c}{ National Coordinates } \\
\hline & Easting $(\mathrm{m})$ & Northing $(\mathrm{m})$ & Easting $(\mathrm{m})$ & Northing $(\mathrm{m})$ \\
\hline PT02 & 1563.3413 & 320.9306 & 243253.0130 & 647775.6970 \\
PT03 & 2000.0069 & 0.0074 & 243784.9144 & 647878.6070 \\
PT04 & 2672.5435 & 118.5967 & $?$ & $?$ \\
\hline
\end{tabular}

$$
A=\left[\begin{array}{cccc}
1563.3413 & -320.9306 & 1.000 & 0.000 \\
320.9306 & 1563.413 & 0.000 & 1.000 \\
2000.0069 & -0.0074 & 1.000 & 0.000 \\
0.0074 & 2000.0069 & 0.000 & 1.000 \\
2672.544 & -118.597 & 1.000 & 0.000 \\
118.597 & 2672.544 & 0.000 & 1.000
\end{array}\right], L=\left[\begin{array}{l}
243253.013 \\
647775.697 \\
243784.914 \\
647878.607 \\
244154.112 \\
648452.897
\end{array}\right], X=\left[\begin{array}{c}
a \\
b \\
T_{E} \\
T_{N}
\end{array}\right]
$$

The solutions of ' $\mathrm{X}$ ' using MATLAB gave the following values for the transformation parameters $a, b$, $T_{E}$ and $T_{N}$.

By substituting the values of ' $A$ ' and ' $L$ ' into equation (12) the solution of ' $X$ ' were determined as follows;

$$
X=\left(\begin{array}{c}
0.6788 \\
07346 \\
242428.034 \\
646410.026
\end{array}\right)
$$

Where; $\mathrm{a}=(0.6788), \mathrm{b}=(0.7346), \mathrm{T}_{E}=(242428.034), \mathrm{T}_{N}=(646410.026)$. 
Figure 3, depicts the screen shot of the MATLAB R2012a interface showing the written scripts, command window and the workspace.

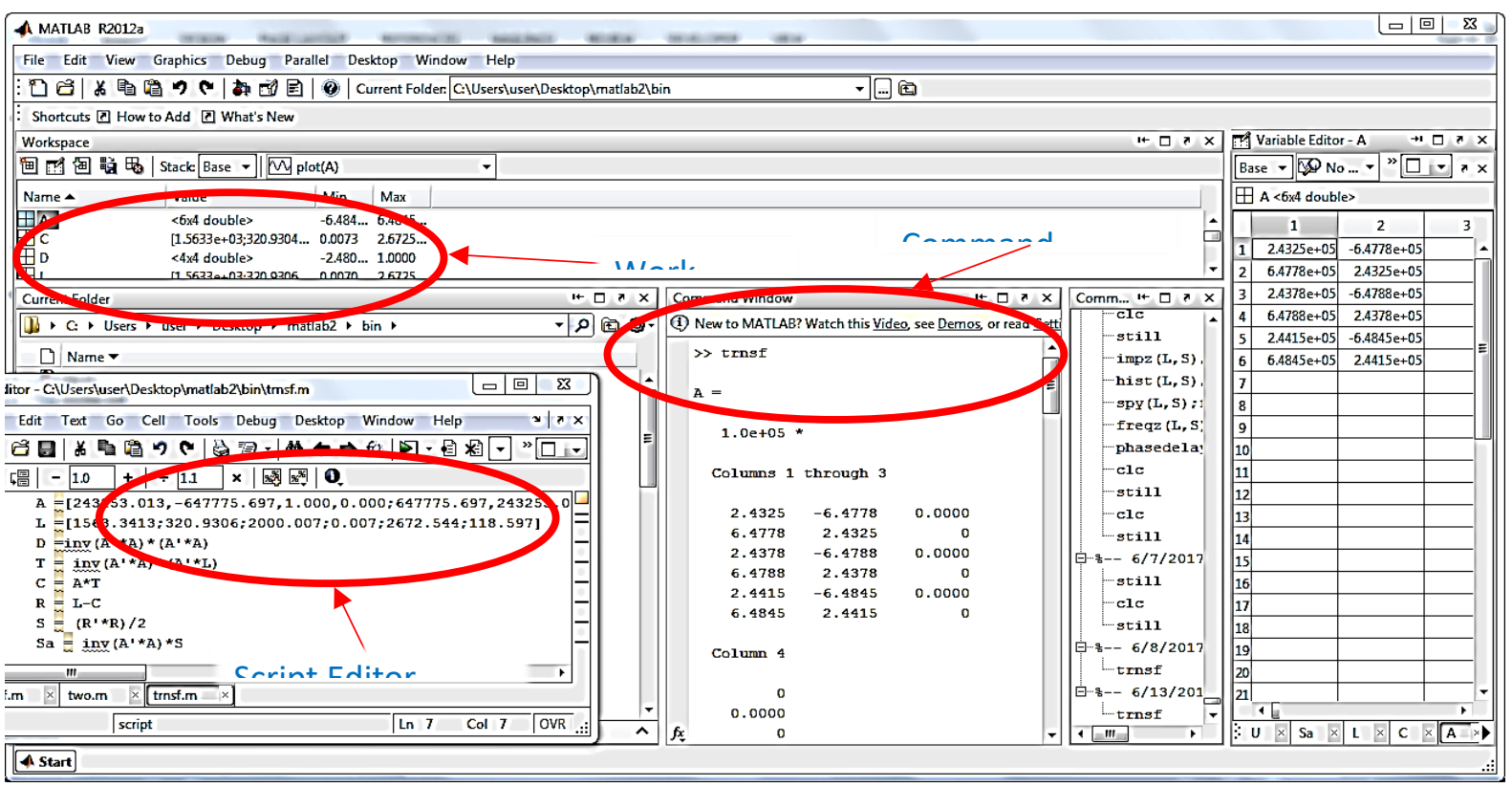

Figure 3: Screen shot of the MATLAB R2012a interface.

From equation (13), making ' $\mathrm{V}$ ' the subject of the formula,

$V=A X-L$

$$
V=\left[\begin{array}{cccc}
1563.3413 & -320.9306 & 1.000 & 0.000 \\
320.9306 & 1563.413 & 0.000 & 1.000 \\
2000.0069 & -0.0074 & 1.000 & 0.000 \\
0.0074 & 2000.0069 & 0.000 & 1.000 \\
2672.544 & -118.597 & 1.000 & 0.000 \\
118.597 & 2672.544 & 0.000 & 1.000
\end{array}\right] *\left(\begin{array}{c}
0.6788 \\
0.7346 \\
(242428.034 \\
646410.026
\end{array}\right]-\left[\begin{array}{l}
243253.013 \\
647775.697 \\
243784.914 \\
647878.607 \\
244154.112 \\
648452.897
\end{array}\right]
$$

The solution of ' $\mathrm{V}$ ' the vector of residual is given as follows;

$$
V=\left[\begin{array}{c}
1.8640 e^{-04} \\
-2.0495 e^{-04} \\
-4.0618 e^{-04} \\
2.1032 e^{-04} \\
2.1977 e^{-04} \\
-5.3680 e^{-06}
\end{array}\right]
$$

From least squares adjustment, sum of squares of the residuals should be minimum. Therefore, the solution of the squares of the residuals gave;

$\sum_{i}^{n} V_{i}^{2}=2.098 e^{-07} m$ 
The solution to the normal equation ' $\mathrm{N}$ ' is given by equation (14) while the solution to the inverse of the normal equation ' $\mathrm{N}^{-1}$ ' for the model is given by equation (15);

$$
N=\left(A^{T} A\right)
$$

$N=\left[\begin{array}{llll}1563.3413 & -320.9306 & 1.000 & 0.000 \\ 320.9306 & 1563.413 & 0.000 & 1.000 \\ 2000.0069 & -0.0074 & 1.000 & 0.000 \\ 0.0074 & 2000.0069 & 0.000 & 1.000 \\ 2672.544 & -118.597 & 1.000 & 0.000 \\ 118.597 & 2672.544 & 0.000 & 1.000\end{array}\right]^{T}\left[\begin{array}{llll}1563.3413 & -320.9306 & 1.000 & 0.000 \\ 320.9306 & 1563.413 & 0.000 & 1.000 \\ 2000.0069 & -0.0074 & 1.000 & 0.000 \\ 0.0074 & 2000.0069 & 0.000 & 1.000 \\ 2672.544 & -118.597 & 1.000 & 0.000 \\ 118.597 & 2672.544 & 0.000 & 1.000\end{array}\right]$

$$
N=\left[\begin{array}{cccc}
13703616.469 & 0 & 6235.892 & 439.535 \\
0 & 13703616.469 & -439.535 & 6235.892 \\
6235.892 & -439.535 & 3 & 0 \\
439.535 & 6235.892 & 0 & 3
\end{array}\right]
$$

$N^{-1}=\left(A^{T} A\right)^{-1}$

$\left(\left[\begin{array}{cccc}1563.3413 & -320.9306 & 1.000 & 0.000 \\ 320.9306 & 1563.413 & 0.000 & 1.000 \\ 2000.0069 & -0.0074 & 1.000 & 0.000 \\ 0.0074 & 2000.0069 & 0.000 & 1.000 \\ 2672.544 & -118.597 & 1.000 & 0.000 \\ 118.597 & 2672.544 & 0.000 & 1.000\end{array}\right]^{T}\left[\begin{array}{llll}1563.3413 & -320.9306 & 1.000 & 0.000 \\ 320.9306 & 1563.413 & 0.000 & 1.000 \\ 2000.0069 & -0.0074 & 1.000 & 0.000 \\ 0.0074 & 2000.0069 & 0.000 & 1.000 \\ 2672.544 & -118.597 & 1.000 & 0.000 \\ 118.597 & 2672.544 & 0.000 & 1.000\end{array}\right]\right)^{-1}$

$$
N^{-1}=\left[\begin{array}{cccc}
1.4688 e^{-06} & -2.6469 e^{-23} & -0.003069 & -0.0002164 \\
-2.6469 e^{-23} & 1.4768 e^{-06} & 0.0002164 & -0.003069 \\
-0.003069 & 0.0002163 & 6.7461 & 0 \\
-0.0002163 & -0.003069 & 0 & 6.7461
\end{array}\right]^{-1}
$$

The standard deviation for the model which shows the accuracy can be computed as follows;

$$
\sigma_{0}^{2}=\frac{V^{T} V}{r}
$$

Where:

" $r$ " is the redundancy, that is, the number of equations minus the number of unknowns. In the case of 3 pairs of points with 6 equations and 4 unknown transformation parameters, the redundancy is $(6-4)=$ 2. The solution to standard deviation of unit weight is shown below.

$$
\sigma_{0}^{2}=\frac{\left[\begin{array}{c}
1.8640 e^{-04} \\
-2.0495 e^{-04} \\
-4.0618 e^{-04} \\
2.1032 e^{-04} \\
2.1977 e^{-04} \\
-5.3680 e^{-06}
\end{array}\right]^{T}\left[\begin{array}{c}
1.8640 e^{-04} \\
-2.0495 e^{-04} \\
-4.0618 e^{-04} \\
2.1032 e^{-04} \\
2.1977 e^{-04} \\
-5.3680 e^{-06}
\end{array}\right]}{2}
$$


$\sigma_{0}^{2}=1.6715 e^{-07}$

The covariance matrix for the transformation parameters when converting from local coordinates to national coordinates can be computed using the relations;

$$
C_{(E, N)}=\sigma_{0}^{2}\left(A^{T} A\right)^{-1}=\sigma_{0}^{2} N^{-1}
$$

Where;

$\sigma^{2}=$ the standard deviation.

$\left(\mathrm{A}^{\mathrm{T}} \mathrm{A}\right)^{-1}=$ Normal coefficient matrix.

$\left.C_{(E, N)}=1.6715 \times 10^{-07} *\left(\left[\begin{array}{llll}1563.3413 & -320.9306 & 1.000 & 0.000 \\ 320.9306 & 1563.413 & 0.000 & 1.000 \\ 2000.0069 & -0.0074 & 1.000 & 0.000 \\ 0.0074 & 2000.0069 & 0.000 & 1.000 \\ 2672.544 & -118.597 & 1.000 & 0.000 \\ 118.597 & 2672.544 & 0.000 & 1.000\end{array}\right]^{T} * \begin{array}{llll}1563.3413 & -320.9306 & 1.000 & 0.000 \\ 320.9306 & 1563.413 & 0.000 & 1.000 \\ 2000.0069 & -0.0074 & 1.000 & 0.000 \\ 0.0074 & 2000.0069 & 0.000 & 1.000 \\ 2672.544 & -118.597 & 1.000 & 0.000 \\ 118.597 & 2672.544 & 0.000 & 1.000\end{array}\right]\right)^{-1}$

The solution of variance co-variance matrix is given as follows with variances at the diagonal and covariances at other corners;

$$
C_{(E, N)}=\left[\begin{array}{cccc}
2.4685 e^{-13} & -4.4243 e^{-30} & -5.1311 e^{-10} & -3.6167 e^{-11} \\
-4.4243 e^{-30} & 2.4685 e^{-13} & 3.6167 e^{-11} & -5.1311 e^{-10} \\
-5.1311 e^{-10} & 3.6167 e^{-11} & 1.1276 e^{-06} & 0 \\
-3.6167 e^{-11} & -5.1311 e^{-10} & 0 & 1.1276 e^{-06}
\end{array}\right]
$$

The standard deviation of the model is computed by taken the square root of the variances which gave the following values respectively.

$$
\begin{aligned}
& \sigma_{a}=\sqrt{2.4685 e^{-13}}=4.96 e^{-07} \mathrm{~m} \\
& \sigma_{b}=\sqrt{2.4685 e^{-13}}=4.96 e^{-07} \mathrm{~m} \\
& \sigma_{T e}=\sqrt{1.1276 e^{-06}}=1.06 e^{-07} \mathrm{~m} \\
& \sigma_{T_{N}}=\sqrt{1.1276 e^{-06}}=1.06 e^{-07} \mathrm{~m}
\end{aligned}
$$

Validation of the model with three control points was verified using equations (18a) and (18b) in which we are able to compute the coordinates of point (PT07). Which we have represented in this case by subscript ' $c$ ' in the national system.

$$
\begin{aligned}
& \left.E_{c}=\text { a(derived }\right) E_{c}^{\text {local }}-b(\text { derived }) N_{c}^{\text {local }}+T_{E}(\text { derived }) \\
& N_{c}=\text { local }(\text { derived }) N_{c}^{\text {local }}+b(\text { derived }) E_{c}+T_{N}(\text { derived })
\end{aligned}
$$

The solutions are as presented below;

$$
\begin{aligned}
& E_{C}=(0.6788 * 2672.5435)-(0.7346 * 118.5967)+(242428.034) \\
& N_{C}=(0.6788 * 118.5967)+(0.7346 * 2672.5435)+(646410.026)
\end{aligned}
$$


$E_{C}=244155.0958 \mathrm{~m}$

$N_{C}=648452.9396 \mathrm{~m}$

The derived national coordinates for PT04 which was represented by question mark in table 1 is as shown below;

$$
\begin{aligned}
& E_{c}=244154.1124 \mathrm{~m} \\
& N_{c}=648452.8972 \mathrm{~m} \\
& \delta E_{c}=0.983 \mathrm{~m} \\
& \delta N_{c}=0.042 \mathrm{~m}
\end{aligned}
$$

\subsection{Designed matrix for observation equation model using four control points}

Table 2 shows the case of having four coordinate data in the local system with three known point in the national, point (PT07) needed to be determined in the national system through transformation.

Table 2: Input data

\begin{tabular}{ccccc}
\hline Point & \multicolumn{2}{c}{ Local Coordinates } & \multicolumn{2}{c}{ National Coordinates } \\
\hline & Easting $(\mathrm{m})$ & Northing $(\mathrm{m})$ & Easting $(\mathrm{m})$ & Northing $(\mathrm{m})$ \\
\hline PT02 & 1563.3413 & 320.9306 & 243253.0130 & 647775.6970 \\
PT03 & 2000.0069 & 0.0074 & 243784.9144 & 647878.6070 \\
PT04 & 2672.5435 & 118.5967 & 244154.1124 & 648452.8972 \\
PT07 & 1624.6415 & 843.4996 & $?$ & $?$ \\
\hline
\end{tabular}

The designed matrices will be in the form;

$$
A X=L+V
$$

$$
A=\left[\begin{array}{cccc}
X_{a} & -Y_{a} & 1 & 0 \\
Y_{a} & X_{a} & 0 & 1 \\
X_{b} & -Y_{b} & 1 & 0 \\
Y_{b} & X_{b} & 0 & 1 \\
X_{c} & -Y_{c} & 1 & 0 \\
Y_{c} & X_{c} & 0 & 1 \\
X_{d} & -Y_{d} & 1 & 0 \\
Y_{d} & X_{d} & 0 & 1
\end{array}\right], X=\left[\begin{array}{c}
a \\
b \\
T_{E} \\
T_{N}
\end{array}\right], L=\left[\begin{array}{c}
X_{a} \\
Y_{a} \\
X_{b} \\
Y_{b} \\
X_{c} \\
Y_{c} \\
X_{d} \\
Y_{d}
\end{array}\right], \text { and }\left[\begin{array}{c}
V_{E_{A}} \\
V_{N_{A}} \\
V_{E_{B}} \\
V_{N_{B}} \\
V_{E_{C}} \\
V_{N_{C}} \\
V_{E_{D}} \\
V_{N_{D}}
\end{array}\right]
$$

The design matrix for four control points will follow the same procedure as before but the principle will be adopted if one needed to transform many points simultaneously. Just by adding one more control point (PT07) to the first three and repeating the processes from equations (12) to (18). The following results were obtained. Recall from equation (12) that we have the solution for matrix X but we differentiate this by introducing subscript 1 here;

$X_{1}=\left(A^{T} A\right)^{-1} A^{T} L$

Putting our parameters for three control stations in matrix form and applying equation (12*) and then solving with MATLAB. But it is important to note that the ' $A$ ' matrix is no longer square. There are 6 rows and 4 columns, therefore, the matrix cannot simply be inverted. Substituting our parameters again give the following resulting for matrix ' $\mathrm{X}_{1}$ '. 


$$
A=\left[\begin{array}{cccc}
1563.341 & -320.930 & 1.000 & 0.000 \\
320.931 & 1563.413 & 0.000 & 1.000 \\
200.007 & -0.007 & 1.000 & 0.000 \\
0.007 & 200.007 & 0.000 & 1.000 \\
2672.544 & -118.597 & 1.000 & 0.000 \\
118.597 & 2672.544 & 0.000 & 1.000 \\
1624.642 & -843.499 & 1.000 & 0.000 \\
843.449 & 1624.642 & 0.000 & 1.000
\end{array}\right], L=\left[\begin{array}{l}
243253.013 \\
647775.697 \\
243784.914 \\
647878.607 \\
244154.112 \\
648452.897 \\
242910.886 \\
648175.241
\end{array}\right], X_{1}=\left[\begin{array}{c}
a \\
b \\
T_{E} \\
T_{N}
\end{array}\right]
$$

The solutions of ' $\mathrm{X}_{1}$ ' using MATLAB gave the following values for the transformation parameters $a$, $b, T_{E}$ and $T_{N}$. Which is still the same as the one obtained with two control points.

$X_{1}=\left(\left[\begin{array}{cccc}1563.341 & -320.930 & 1.000 & 0.000 \\ 320.931 & 1563.413 & 0.000 & 1.000 \\ 200.007 & -0.007 & 1.000 & 0.000 \\ 0.007 & 200.007 & 0.000 & 1.000 \\ 2672.544 & -118.597 & 1.000 & 0.000 \\ 118.597 & 2672.544 & 0.000 & 1.000 \\ 1624.642 & -843.499 & 1.000 & 0.000 \\ 843.449 & 1624.642 & 0.000 & 1.000\end{array}\right]^{T} *\left[\begin{array}{cccc}1563.341 & -320.930 & 1.000 & 0.000 \\ 320.931 & 1563.413 & 0.000 & 1.000 \\ 200.007 & -0.007 & 1.000 & 0.000 \\ 0.007 & 200.007 & 0.000 & 1.000 \\ 2672.544 & -118.597 & 1.000 & 0.000 \\ 118.597 & 2672.544 & 0.000 & 1.000 \\ 1624.642 & -843.499 & 1.000 & 0.000 \\ 843.449 & 1624.642 & 0.000 & 1.000\end{array}\right]\right)^{-1} *$

$\left[\begin{array}{cccc}1563.341 & -320.930 & 1.000 & 0.000 \\ 320.931 & 1563.413 & 0.000 & 1.000 \\ 200.007 & -0.007 & 1.000 & 0.000 \\ 0.007 & 200.007 & 0.000 & 1.000 \\ 2672.544 & -118.597 & 1.000 & 0.000 \\ 118.597 & 2672.544 & 0.000 & 1.000 \\ 1624.642 & -843.499 & 1.000 & 0.000 \\ 843.449 & 1624.642 & 0.000 & 1.000\end{array}\right]^{T} *\left[\begin{array}{l}243253.013 \\ 647775.697 \\ 243784.914 \\ 647878.607 \\ 244154.112 \\ 648452.897 \\ 242910.886 \\ 648175.241\end{array}\right]$

The solution to matrix ' $\mathrm{X}_{1}$ ' is the same as we have in matrix ' $\mathrm{X}$ ', for $a, b, T_{E}$ and $T_{N}$ respectively.

$$
X_{1}=\left(\begin{array}{c}
0.6788 \\
0.7346 \\
242428.034 \\
646410.026
\end{array}\right)
$$

Where; $\mathrm{a}=(0.6788), \mathrm{b}=(0.7346), \mathrm{T}_{E}=(242428.034), \mathrm{T}_{N}=(646410.026)$.

From equation (13), making ' $V$ ' the subject of the formula.

$V=A X_{1}-L$ 


$V=\left[\begin{array}{cccc}1563.341 & -320.930 & 1.000 & 0.000 \\ 320.931 & 1563.413 & 0.000 & 1.000 \\ 200.007 & -0.007 & 1.000 & 0.000 \\ 0.007 & 200.007 & 0.000 & 1.000 \\ 2672.544 & -118.597 & 1.000 & 0.000 \\ 118.597 & 2672.544 & 0.000 & 1.000 \\ 1624.642 & -843.499 & 1.000 & 0.000 \\ 843.449 & 1624.642 & 0.000 & 1.000\end{array}\right] *\left(\begin{array}{c}0.6788 \\ 0.7346 \\ 242428.034 \\ 646410.026\end{array}\right]-\left[\begin{array}{l}243253.013 \\ 647775.697 \\ 243784.914 \\ 647878.607 \\ 244154.112 \\ 648452.897 \\ 242910.886 \\ 648175.241\end{array}\right]$

The solution of ' $\mathrm{V}$ ' is given as follows;

$$
V=\left[\begin{array}{c}
9.1702 e^{-04} \\
8.1558 e^{-05} \\
-2.0187 e^{-04} \\
3.4292 e^{-04} \\
1.0621 e^{-04} \\
-4.8635 e^{-04} \\
-8.2137 e^{-04} \\
6.1873 e^{-05}
\end{array}\right]
$$

From least squares adjustment, sum of squares of the residuals should be minimum. The solution of the squares of the residuals gave;

$$
\sum_{i}^{n} V_{i}^{2}=0.00000103
$$

The solution to the normal equation ' $\mathrm{N}$ ' and the inverse of the normal equation ' $\mathrm{N}^{-1}$ ' for the model is given by $\left(14^{*}\right)$ and $\left(15^{*}\right)$ respectively;

$$
N=\left(A^{T} A\right)
$$

$N^{-1}=\left(A^{T} A\right)^{-1}$

$N=\left[\begin{array}{cccc}1563.341 & -320.930 & 1.000 & 0.000 \\ 320.931 & 1563.413 & 0.000 & 1.000 \\ 200.007 & -0.007 & 1.000 & 0.000 \\ 0.007 & 200.007 & 0.000 & 1.000 \\ 2672.544 & -118.597 & 1.000 & 0.000 \\ 118.597 & 2672.544 & 0.000 & 1.000 \\ 1624.642 & -843.499 & 1.000 & 0.000 \\ 843.449 & 1624.642 & 0.000 & 1.000\end{array}\right]^{T}\left[\begin{array}{cccc}1563.341 & -320.930 & 1.000 & 0.000 \\ 320.931 & 1563.413 & 0.000 & 1.000 \\ 200.007 & -0.007 & 1.000 & 0.000 \\ 0.007 & 200.007 & 0.000 & 1.000 \\ 2672.544 & -118.597 & 1.000 & 0.000 \\ 118.597 & 2672.544 & 0.000 & 1.000 \\ 1624.642 & -843.499 & 1.000 & 0.000 \\ 843.449 & 1624.642 & 0.000 & 1.000\end{array}\right]$




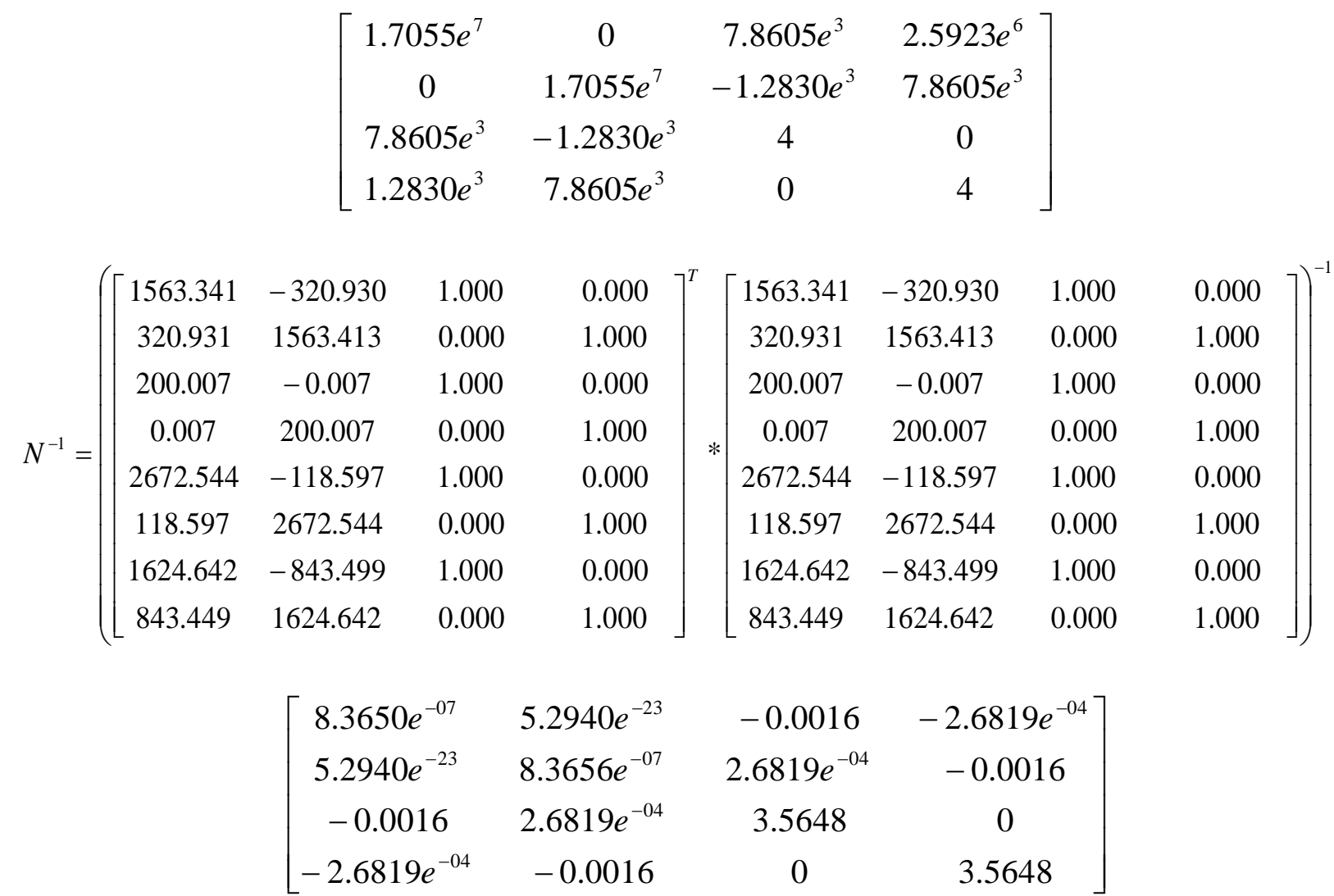

The standard deviation for the model which shows the accuracy can be computed as follows;

$$
\sigma_{0}^{2}=\frac{V^{T} V}{r}
$$

Where " $r$ " is the redundancy, that is, the number of equations minus the number of unknowns. In the case of 4 pairs of points with 8 equations and 4 unknown transformation parameters, the redundancy is $(8-4)=4$. The solution to standard deviation of unit weight is shown below .

$$
\sigma_{0}^{2}=\frac{\left[\begin{array}{c}
9.1702 e^{-04} \\
8.1558 e^{-05} \\
-2.0187 e^{-04} \\
3.4292 e^{-04} \\
1.0621 e^{=04} \\
-4.8635 e^{-04} \\
-8.2137 e^{-04} \\
6.1873 e^{=05}
\end{array}\right]^{T} *\left[\begin{array}{c}
9.1702 e^{-04} \\
8.1558 e^{-05} \\
-2.0187 e^{-04} \\
3.4292 e^{-04} \\
1.0621 e^{=04} \\
-4.8635 e^{-04} \\
-8.2137 e^{-04} \\
6.1873 e^{=05}
\end{array}\right]}{4}
$$

$\sigma_{0}^{2}=4.8306 e^{-07}$

The covariance matrix for the transformation parameters when converting from local coordinates to standard coordinates can be computed using the relations;

$C_{(E, N)}=\sigma_{0}^{2}\left(A^{T} A\right)^{-1}=\sigma_{0}^{2} N^{-1}$

Where;

$\sigma^{2}{ }_{0}=$ the standard deviation.

$\left(\mathrm{A}^{\mathrm{T}} \mathrm{A}\right)^{-1}=$ Normal coefficient matrix. 


$$
C_{(E, N)}=4.8306 e^{-07} *\left(\left[\begin{array}{cccc}
1563.341 & -320.930 & 1.000 & 0.000 \\
320.931 & 1563.413 & 0.000 & 1.000 \\
200.007 & -0.007 & 1.000 & 0.000 \\
0.007 & 200.007 & 0.000 & 1.000 \\
2672.544 & -118.597 & 1.000 & 0.000 \\
118.597 & 2672.544 & 0.000 & 1.000 \\
1624.642 & -843.499 & 1.000 & 0.000 \\
843.449 & 1624.642 & 0.000 & 1.000
\end{array}\right]^{T} *\left[\begin{array}{cccc}
1563.341 & -320.930 & 1.000 & 0.000 \\
320.931 & 1563.413 & 0.000 & 1.000 \\
200.007 & -0.007 & 1.000 & 0.000 \\
0.007 & 200.007 & 0.000 & 1.000 \\
2672.544 & -118.597 & 1.000 & 0.000 \\
118.597 & 2672.544 & 0.000 & 1.000 \\
1624.642 & -843.499 & 1.000 & 0.000 \\
843.449 & 1624.642 & 0.000 & 1.000
\end{array}\right]\right)^{-1}
$$

The solution of variance co-variance matrix is given as follows with variances at the diagonal and covariances at other corners;

$$
\left.C_{(E, N}\right)=\left[\begin{array}{cccc}
4.0389 e^{-13} & 2.5573 e^{-29} & -7.9369 e^{-10} & -1.2955 e^{-10} \\
2.5573 e^{-29} & 4.0389 e^{-13} & 1.2955 e^{-10} & -1.8077 e^{-05} \\
-7.9369 e^{-10} & 1.2955 e^{-10} & 1.7220 e^{-06} & 0 \\
-1.2955 e^{-10} & -7.9369 e^{-10} & 0 & 1.7220 e^{-06}
\end{array}\right]
$$

The standard deviation of the model is computed by taken the square root of the variances which gave the following values respectively.

$$
\begin{gathered}
\sigma_{a}=\sqrt{4.0389 e^{-13}}=0.003 \mathrm{~m} \\
\sigma_{b}=\sqrt{4.0389 e^{-13}}=0.003 \mathrm{~m} \\
\sigma_{T_{E}}=\sqrt{1.7220 e^{-06}}=0.065 \mathrm{~m} \\
\sigma_{T_{N}}=\sqrt{1.7220 e^{-06}}=0.065 \mathrm{~m}
\end{gathered}
$$

Validation of the model with four control points was verified using equations $\left(18 \mathrm{a}^{*}\right)$ and $\left(18 \mathrm{~b}^{*}\right)$ in which we are able to compute the coordinates of point (PT07). Which we have represented in this case by'd' in the national system.

$$
\begin{aligned}
& E_{d}=a(\text { derived }) E_{d}^{\text {local }}-b(\text { derived }) N_{d}^{\text {local }}+T_{E}(\text { derived }) \\
& N_{d}=a(\text { derived }) N_{d}^{\text {local }}+b(\text { derived }) E_{d}^{\text {local }}+T_{N}(\text { derived })
\end{aligned}
$$

The solutions are as presented below;

$$
\begin{aligned}
& E_{d}=(0.6788 * 1624.6415)-(0.7346 * 843.4996)+(242428.031) \\
& N_{d}=(0.6788 * 843.4996)+(0.7346 * 1624.6415)+(646410.026) \\
& E_{d}=242911.132 \mathrm{~m} \\
& \mathrm{~N}_{\mathrm{d}}=648176.200 \mathrm{~m}
\end{aligned}
$$

The derived national coordinates for PT07 which was represented by question mark in table 2 is as shown below;

$$
\begin{gathered}
E_{d}=242910.207 \mathrm{~m} \\
N_{d}=648176.544 \mathrm{~m} \\
\delta E_{d}=0.925 \mathrm{~m} \\
\delta N_{d}=0.344 m
\end{gathered}
$$




\subsection{Summary and Conclusion}

This project carried out for deformation monitoring of the dam was carefully executed and twodimensional conformal coordinate transformation was demonstrated using three control points whose value are known in both local and national coordinates systems over a small area. After which four control points were used to demonstrate how subsequent points were transformed in the area. In conclusion, this transformation procedure proved to be very useful where coordinates in local are needed in national values. The easting and northing of third point (PT04) and fourth point (PT07) were computed and presented in order to validate the correctness of the conformal coordinate transformation parameters derived using three and four control points respectively. The same transformation parameter values where obtained using three and four control points, this suggest that each additional point will not alter the values of transformation parameters. Using the method of least squares to transform several points is the best especially when there are several points to be transformed simultaneously. In general, the overall parameters derived are;

(i) Scale $=1.0003$, calculated using $\left(\tan ^{-1}[\mathrm{~b} / \mathrm{a}]\right)$

(ii) Rotation $=47^{0} 15^{\prime} 57.56^{\prime \prime}$, calculated using $([\mathrm{a} / \cos \theta])$ or $([\mathrm{b} / \sin \theta])$

(iii) $\mathrm{a}=0.6788$

(iv) $\mathrm{b}=0.7346$

(v) Translation $\left(\mathrm{T}_{\mathrm{E}}\right)=242428.031$

(vi) Translation $\left(\mathrm{T}_{\mathrm{N}}\right)=646410.026$

Parameters (iii) - (vi) above are the solution of matrix (X).

The following recommendations arise from the results of this study:

- Geomatics and Civil Engineers can get rid of the problem of moving from one coordinate system to another especially when working in an area where local coordinate of at least two points are available and the national coordinate of same points are known. Then is possible to get the national coordinates of the same points and all other points over a given area for instance on a construction sites.

- With the procedure carefully followed, two-dimensional coordinate transformation can be easily performed and this paper has demonstrated that effectively.

\section{References}

Andriy B., (2015) "How to calculate the standard error using MATLAB" accessed June 13, 2017

Barry F. Kavanagh and S.J. Glenn Bird, (2000) “Surveying”, Fifth edition, New Jersey.

Deakin R. E., (1998) “3D Coordinate Transformations”. (Published in Surveying and Land Information Systems, Vol.58, No.4, Dec.1998, pp.223-34)Department of Land Information RMIT University GPO Box 2476V Melbourne Vic 3001Australia

Jayanta K.G, Ojasa and Goyal, (2009) "Establishment of Local Control Points for Mapping using GPS" https://www.geospatialworld.net/article/establishment-of-local-control-points-for-mapping-using-gps

Jim McCoy P.E. and Alain Robert (2012) "Convert Local Coordinate Systems to Standard Coordinate Systems Using 2D Conformal Transformation in MicroStation V8i and Bentley Map V8i"

Mikhail, E.M, (1976) “Observation and Least Squares” IEP, A Don-Donnelly New York.

Paul R.W., (2000) "Element of photogrammetry with application in GIS" $3^{\text {rd }}$ edition McGraw Hill, New York

Shoichi Oki, (2011) "Control Point Surveying and Topographic Mapping" Civil Engineering - Vol. I Encyclopedia of Life Support Systems (EOLSS) Land Bureau, National Land Agency, Japan http://www.eolss.net/sample-chapters/c05/e6-37-02-01.pdf

Uzodinma V. N. and Ehigiator-Irughe R. (2013) "Removal of Inconsistencies Arising from Multiplicity of Transformation Parameters in Nigeria" FIG Working Week 2013 Environment for Sustainability Abuja, Nigeria, 6 - 10 May 2013. 